Foro Interno. Anuario de Teoría Política

ISSN: 1578-4576

\title{
Sobre los valores y los principios para la actuación de los servidores públicos
}

\author{
Ana Elena Fierro ${ }^{1}$; Adonay Otero ${ }^{2}$
}

Recibido: 11 de agosto de 2017/ Aceptado: 29 de diciembre de 2017

Resumen. Los servidores públicos no siempre actúan en función del interés de la comunidad a pesar de las amenazas y sanciones establecidas en el derecho; es necesario encontrar nuevas vías de actuación para resolver tan importante problema. En ese sentido, este artículo busca fundamentar los principios que deben regir la actuación de los mismos. Para ello, en primer lugar, se intenta establecer un método que permita la creación de estos principios, basándose en la teoría del valor de Luis Villoro y en la ética de Immanuel Kant. Posteriormente, se identifica el interés público como aquel valor que se busca por él mismo sin necesidad de acudir a otros valores para cuyo fin esté dispuesto. A continuación, se derivan los valores de responsabilidad, objetividad, imparcialidad, razonabilidad, publicidad, solidaridad, prudencia e instrumentalidad, a partir de los cuáles se construyen principios éticos que puedan, posteriormente, ser positivizados en el derecho.

Palabras clave: Ética pública; filosofía política; valores de la actuación pública; principios éticos públicos; marco normativo de la acción pública y gubernamental.

\section{[en] On the Values and Principles that Determine the Actions of Public Servants}

\begin{abstract}
Public servants do not always act in the interest of the community even though legal sanctions to corruption exist. Therefore, it is necessary to find new ways to solve such an important problem. This article seeks to outline the foundations of the principles that should govern the behavior of public servants. To do this, we first try to establish a method that allows for the creation of these principles, based on Luis Villoro's theory of value and Immanuel Kant's ethics. This leads to identifying the public interest as a value to be pursued in and of itself. From this one may then derive the values of responsibility, objectivity, impartiality, reasonableness, publicity, solidarity, prudence and instrumentality, from which ethical principles are built and subsequently positivized into law.

Keywords: Public ethics; political philosophy; values of public actions; public ethical principles; regulatory framework of public and governmental action.
\end{abstract}

Cómo citar: Ana Elena Fierro y Adonay Otero, "Sobre los valores y los principios para la actuación de los servidores públicos”: Foro Interno. Anuario de Teoría Política, vol. 18 (2018), pp. 7-26.

\footnotetext{
1 Centro de Investigación y Docencia Económicas, CIDE (México)

E-mail: ana.fierro@cide.edu

2 Centro de Investigación y Docencia Económicas, CIDE (México)

E-mail: adonay.otero@cide.edu
} 


\section{Introducción}

La corrupción es uno de los grandes retos de los Estados en el siglo veintiuno. Escándalos continuos como los de Brasil, Rumanía y México develan intrincadas redes de funcionarios, empresarios y delincuentes que operan a espaldas del derecho, poniendo a prueba los sistemas para combatirlos. En general, los mecanismos implementados se han concentrado en el combate mediante el fortalecimiento de las fiscalías, la creación de comisiones especiales o el nombramiento de fiscales o jueces especializados. Dicho de otra manera, se ha endurecido el aparato coercitivo. Mientras se espera con ello combatir o disuadir estas conductas, los resultados, hay que decirlo, han sido más bien discretos.

De ahí que en este ensayo se busque explorar otra vía, consistente en poner el énfasis en los valores que deben regir la conducta de los servidores públicos, entendidos como los guardianes del interés público. Así, se analiza la necesidad de establecer principios que guíen el desempeño de sus funciones para la búsqueda del bienestar de la comunidad, además de la importancia de positivizarlos en el derecho de modo que se conviertan en reglas del quehacer gubernamental. Con ello, este trabajo busca, como afirma Luigi Ferrajoli, lograr que los valores de la ética pública sean parte de la legitimación interna del actuar de los servidores públicos y que guíen de forma efectiva sus acciones, sobre todo, si estos principios son exigibles por vías jurídicas ${ }^{3}$.

Este trabajo se centrará especialmente en ciertos aportes a la fundamentación de los principios que deben regir el actuar de los servidores públicos. Para lograr dicha fundamentación, se comenzará con la distinción entre valores y principios, denotando que los valores son propiedades objetivas de la acción, pero que los principios son ya el imperativo que mandata realizarlos. La perspectiva del concepto de valor y el de principio partirá, en el primer caso, de Luis Villoro (1922-2014) y su obra El poder y el valor; y en el segundo, de Immanuel Kant (1724-1804) desde su obra Fundamentación metafísica de las costumbres, pues el tratamiento que se dará al concepto de principio es el del imperativo categórico.

Cabe mencionar que utilizaremos la obra mencionada de Villoro porque en ella se enfrentó con el problema de establecer una serie de valores que merezcan ser estimados por cualquiera, en cualquier sociedad y en cualquier tiempo. De ahí el subtítulo de su texto: Fundamentos de una ética política. Consideramos, por ello, que los valores que descubre a lo largo de su análisis son relevantes, sobre todo porque este trabajo representa un análisis contemporáneo y profundamente embebido de las características propias de nuestra sociedad democrática — entre ellas la injusticia que parece estar enraizada en muchos de los Estados actuales ${ }^{4}$.

Posteriormente, este trabajo buscará ahondar en los valores propios de la ética pública y para ello se utilizará también la obra de Villoro anteriormente mencionada, además de otros autores que resultan relevantes por haber teorizado sobre nuestro objeto de estudio. Una vez determinados los valores correspondientes, se usarán para crear una máxima que será sometida a la prueba del imperativo categórico para, de resultar

Luigi Ferrajoli, Democracia y garantismo, ed. de Miguel Carbonell, Trotta, Madrid, 2008, pp. 51-64.

4 Luis Villoro, Los retos de la sociedad por venir: ensayos sobre justicia, democracia y multiculturalismo, Fondo de Cultura Económica, México, 2007; Luis Villoro, Estado plural, pluralidad de culturas, Editorial Paidós, México, 2001. 
adecuada, considerar que a partir de ella se ha creado un principio que tiene la propiedad de ser universal y, por lo tanto, que podrá ser incorporado al orden jurídico dentro de las normas supremas y desarrollado a través de los códigos de ética pública.

\section{De la teoría del valor y los principios del actuar de los servidores públicos}

El ejercicio del poder parte de un marco normativo que faculta a sus actores para hacer ciertas acciones que están enderezadas a los objetivos propios de las instituciones que son, a su vez, el motivo por el que fueron creadas. Las acciones valiosas, en ese sentido, son las que se ajustan a dichos propósitos. No obstante, quienes ejercen el poder son individuos que tienen deseos particulares que muchas veces entran en contradicción con los valores institucionales. Por esta razón deberán plantearse principios éticos y jurídicos, para llegar con mayor seguridad a la consecución de los objetivos de las instituciones públicas.

La presente sección busca establecer un método para obtener esos principios que sea transversal a todas las instituciones públicas; para ello es necesario que dichos valores puedan ser universalizables y, con ello, se pueda establecer un grupo de ellos que se deban seguir en todas las instituciones públicas.

\subsection{De la relación entre los valores y los principios: bosquejo de un método}

El valor, según el pensador mexicano Luis Villoro, se define como "las características por las que un objeto o situación es término de una actitud favorable"s. Esta actitud, a su vez, se entiende como una disposición adquirida de la voluntad que se dirige hacia una cualidad de un objeto o situación de una manera favorable o desfavorable. Así, en principio, los valores son objetivos en tanto cualidades de la acción. Pero el problema que sale al paso es que los valores por ellos mismos no conducen la actuación si no se han vuelto normas. Esto es especialmente relevante en el caso de las instituciones públicas, pues el individuo tiene que servir a un interés que no es el particular, por lo que, como veremos, constantemente se produce una relación antagónica entre los valores individuales y los valores públicos.

Empero, hay una relación estrecha entre el valor y el principio. Esto se puede observar en que el principio obliga a la acción de una cierta manera y, en su diseño, dicho principio es deseable; es decir: valioso. Así, primero se determina que ciertas conductas son valiosas y, posteriormente, surge la necesidad de exigir esa conducta a través de principios éticos. Además, en el caso de las instituciones públicas, esos principios deben estar positivizados; es decir, incorporados en el orden jurídico, por lo que su mandato es aún más fuerte al ser exigible de manera coercitiva.

Estos principios, a su vez, deben estar en relación de sujeción al bien, por el cual, en este particular contexto, entendemos como la voluntad de actuar en favor del interés público. Esta buena voluntad es, en efecto, lo que Kant argumentaba en la Fundamentación metafísica de las costumbres como lo verdaderamente importante para determinar que una acción es buena:

Luis Villoro, El poder y el valor. Fundamentos de una ética politica, Fondo de Cultura Económica, México, 1997, p. 13. 
El entendimiento, el gracejo, el juicio, o como quieran llamarse los talentos del espíritu; el valor, la decisión, la perseverancia en los propósitos, como cualidades del temperamento, son, sin duda, en muchos respectos, buenos y deseables; pero también pueden llegar a ser extraordinariamente malos y dañinos si la voluntad que ha de hacer uso de estos dones de la naturaleza, y cuya peculiar constitución se llama por eso carácter, no es buena ${ }^{6}$.

De esta manera, los valores son importantes, pero no por sí mismos, sino que antes de ellos se encuentra la buena voluntad, que es la que debe dirigir la acción.

Por lo tanto, los valores para Kant funcionan solo si están enraizados en una voluntad buena, por ello son secundarios. Lo único que importa para caracterizarlos como buenos es la obediencia a la ley moral que previamente es entregada por la razón. Así, esta buena voluntad no es salvaje, sino que, guiada por la razón, establece una serie de principios universales cuyo mandato la constriñe a actuar de un determinado modo ${ }^{7}$. Como el objetivo de la razón es entregarnos, precisamente, lo que una voluntad buena debe desear, también puede determinar los principios que deben regir la voluntad. En este sentido, el principio más importante es el imperativo categórico por ser el que facilita el objetivo último que debe cumplir la razón.

Dicho principio es una ley moral irrestricta - es decir, es válido para todos los seres racionales en cualquier situación - que determina el requisito fundamental que debe cumplir cualquier acción para ser considerada buena. Este fue enunciado como "obra solo según una máxima tal que puedas querer al mismo tiempo que se torne ley universal"». Una buena acción será entonces la que siga el imperativo. Pero este imperativo es meramente formal, está desprovisto de todo contenido. Por lo cual la relación que existe entre dicho imperativo y los valores es que mientras que el primero determina la regla para crear principios éticos; los valores, por su parte, se convierten en la parte material ${ }^{9}$ que, por medio de una síntesis con el imperativo categórico, construyen los principios éticos específicos que deben regir la conducta de los servidores públicos. Esto es así porque los valores pueden ser ellos mismos constitutivos de máximas.

A modo de ejemplo, podríamos pensar en una situación específica como el deber del servidor público de prestar los servicios para los cuales está facultado sin recibir un beneficio personal a cambio. En ese estado de cosas, el valor manifiesta una cualidad valiosa de la acción pública que puede conceptualizarse como el valor de la honestidad. En tanto que solo nos quedemos en este simple valor, nada establece como deber el actuar en función del mismo. Bien podría tal persona decir: "Si bien la honestidad es valiosa, en este momento pediré dinero por prestar el servicio, ya que todos mis compañeros lo hacen". Sin embargo, si transformamos ese valor en una máxima, digamos: "Siempre que alguien preste un servicio público deberá de actuar honestamente" y se añade como contenido del imperativo categórico, se puede establecer una norma universal que constriñe la acción. Esto es lo que, en los límites de este trabajo, se entiende como principio ético, lo que surge de la conjunción entre la

\footnotetext{
Immanuel Kant, Fundamentación de la metafisica de las costumbres, texto íntegro de la trad. de Manuel García Morente, ed. de Pedro M. Rosario Barbosa, San Juan, Puerto Rico, 2007, p. 7. Publicado bajo licencia Creative Commons. Disponible en: https://pmrb.net/books/kantfund/fund_metaf_costumbres_vD.pdf (1-8-2017).

Ibid., p. 10.

Ibid., p. 35.

Por materia entendemos el contenido que en conjunción con la forma crean un principio concreto.
} 
parte material — que es el valor objetivo - y la norma formal — que, en este caso, es el imperativo categórico-.

Asimismo, como piensa Ferrajoli, una vez establecidos los principios, es posible incorporarlos al derecho, de modo que dejen de ser una fuente de legitimación externa de la conducta de las persona para convertirse en fuentes de legitimación interna que califican y guían la acción gubernamental ${ }^{10}$. De modo que al positivizar el principio ético en una norma jurídica se convierte en una directriz de la conducta exigible a través del derecho, siempre que se preste un servicio público debe hacerse sin recibir un beneficio personal a cambio.

\section{Del interés público como valor intrínseco}

Como este trabajo busca entender la fundamentación de valores específicos de la ética pública, el imperativo categórico, al ser formal, - es decir, desprovisto de todo contenido - es útil una vez que se hayan determinado estos valores y se hayan creado máximas con ellos. Dado que la ética pública es un modo de la ética en general, se requieren explorar los valores que fundamentan los principios específicos, y solo después de realizado podrá incluirse la parte formal para derivar los principios éticos que nacen de la conjunción material-formal, ciertamente, como en las matemáticas el producto nace de sus factores.

Pero ¿cuáles son estos valores?, ¿son todos iguales o entre ellos hay diferencias? En principio, puede decirse, con Villoro, que hay dos tipos de valores: aquellos que se buscan por ellos mismos, y aquellos que se buscan en función de otro valor. Por ejemplo, los valores como una buena dieta, el ejercicio, etc., son valiosos, pero solo en función de que ellos propician un valor deseado por él mismo; en este caso, la salud. Esta diferencia entre los valores es lo que el filósofo mexicano llama valores extrínsecos e intrínsecos, respectivamente. Dice: “en general, un objeto tiene valor extrínseco solo si posee las propiedades que se requieren para obtener un determinado valor intrínseco; no tiene por lo tanto valor sustantivo, sino solo relativo a la realización de otro valor que apreciemos por él mismo" "11. Así, los valores extrínsecos son utilitarios, en el sentido de que son útiles, y dependen del valor intrínseco. En ese sentido, primero hay que determinar cuál o cuáles son los valores intrínsecos. Estos serán las finalidades y de ellas podrán determinarse los medios, es decir, los valores extrínsecos.

Ahora bien, ¿cuál es el valor intrínseco de los servidores públicos? Una aproximación es que los servidores públicos tutelan el interés de todos. Dicho de otra manera, son los guardianes del interés público y este es la finalidad de sus servicios, a la cual deben de estar enderezadas todas sus acciones.

Autores como Rabotnikof, Tyler, Bo y Persons apuntan que el interés público es el objeto de la actuación gubernamental y, por ende, la guía del servicio público ${ }^{12}$. En

Ferrajoli, Democracia y garantismo, pp. 73-85.

Villoro, El poder y el valor, p 20.

Ann Persson, Bo Rothstein y Jan Teorell, The Failure of Anti-Corruption Policies. A Theoretical Mischaracterization of the Problem, QoG Working Paper Series 2010:19, The Quality of Government Institute, Department of Political Science, University of Gothenburg, Göteborg, Junio 2010; Nora Rabotnikof, En busca de un lugar común. El espacio público en la teoría política contemporánea, Instituto de Investigaciones Fi- 
ese sentido, el interés público puede definirse como el bien común. Si bien este no es el espacio para analizar a fondo el concepto de interés público, baste con señalar que se entiende como fin de la acción gubernamental y, por tanto, todo servicio público debe encaminarse justamente a ese interés, independientemente de la institución pública de la que se trate. En suma, el interés público es el valor intrínseco del que, más tarde, se derivarán los valores subordinados.

Cabe mencionar, que la ética pública está conformada por los principios que encontramos en comunidades humanas y en eso se encuentra su especificidad. Una ética puede referirse meramente a un individuo que actúa en función de lo que considera bueno para sí, y el bien será entonces de carácter personal, aunque pudiese desear que todos buscaran ese valor. No obstante, la ética pública, al partir de una comunidad de sujetos, no puede partir de un bien para uno, sino que tiene que ser un bien para todos y esto implica que el bien buscado tiene un carácter común. No es, pues, lo relativo a una persona, sino a un conjunto de personas, es decir, a una comunidad.

No obstante, Villoro señala que el valor intrínseco que debería de regir el interés público es informulable ${ }^{13}$. Esto, porque en el mundo no existe una sola comunidad, sino una gran variedad de ellas. En ese sentido, aparentemente tendríamos que tomar una comunidad específica para después determinar cuál es el valor querido por la comunidad y a partir de ello derivar los valores instrumentales a dicho fin. Esto volvería necesario tener tantas teorías de valores como comunidades, lo que entra en contradicción con la pretensión de la ética pública de ser una y la misma para todas las instituciones. Para resolver este problema, Villoro menciona que "[1]os intereses y fines personales son variados, pero cualesquiera que sean, en cuanto miembros de una asociación, les unen las mismas relaciones sociales, comparten un interés común: el de satisfacer necesidades inherentes a todo elemento de la asociación"14.

Cabe resaltar que estas "necesidades inherentes" no son tan heterogéneas como podría pensarse. A pesar de que hay muchas comunidades, lo cierto es que todas tienen en común estar constituidas por seres humanos. Estos tienen necesidades que, podríamos decir, son biológicas. De manera análoga, tanto Baruch Spinoza (16321677), como Arthur Schopenhauer (1788-1860) y Miguel de Unamuno (1864-1936), argumentaron que esta necesidad fundamental es el deseo de seguir viviendo ${ }^{15}$. De ahí puede verse que el interés público busca garantizar todos los valores que garantizan la vida de las comunidades, de donde resulta que, al menos en este nivel, las necesidades inherentes de los individuos son universales y se sintetizan en bienes jurídicos tutelados que se pueden llamar de la vida.

Adicionalmente a estos valores, también se encuentran aquellos que dependen de cada hombre concreto en función de lo que considere que es la vida más digna de ser vivida, y en este lugar encontramos todas las posibilidades en el espectro de lo que significa ser humano. Las profesiones y los oficios, la necesidad de desarrollar

losóficas, UNAM, México, 2005, capítulos I, VII y VIII; Bo Rothstein y Jan Theorell, "What is the Quality of Government? A Theory of Impartial Government Institutions": Governance: an International Journal of Policy, Administration, and Institutions, vol. 21, n. 2 (2008), pp. 165-190.

13 Villoro, El poder y el valor, p. 59.

14 Ibidem.

15 Miguel de Unamuno, Del sentimiento trágico de la vida, Ediciones B, Barcelona, 1988; Baruch Spinoza, Ética demostrada según el orden geométrico, trad. de Vidal Peña, Orbis, Buenos Aires, 1983; Arthur Schopenhauer, El mundo como voluntad y representación, vol. I, Trotta, Madrid, 2003. 
las habilidades intelectuales a través de la educación, la elección del trabajo, y todo lo que entraña como posibilidad de ser, son bienes que pueden denominarse de la libertad. En este orden de ideas, Hannah Arendt (1906-1975) argumenta en "¿Qué es la libertad?" que el Estado debe de abrir espacios para el ejercicio de la libertad ${ }^{16}$. Además, este acceso se garantiza a través de las instituciones públicas creadas en función de ello.

De lo dicho más arriba puede entenderse que el Estado tendrá deberes respecto del mínimo de subsistencia de sus ciudadanos y ciertos límites de su actuación para el respeto de la libertad de los modos en que los ciudadanos deseen hacer su vida. A esto se añade el problema de que hay modos de vida ciertamente ilegales, por lo que el Estado sí que puede restringir ciertos modos de vida, si atenta contra sus leyes positivas, pero, dentro de los límites de lo legal, le corresponde a cada individuo seguir sus propias inclinaciones sobre lo que considera su modo de la vida. Así, se entiende que un Estado constitucional es aquel que se establece de manera democrática, respeta y promueve los derechos humanos como medios para el pleno desarrollo de los individuos. Para ello determina como fin primordial del Estado el interés público.

En suma, el interés público se compone de los bienes de la vida y la libertad, y de ello nacen las instituciones públicas como encargadas de protegerlos. Lo que cabe resaltar de esos componentes del interés público es que son comunes. En ese sentido, el servidor público no puede utilizarlos para beneficiarse de manera privada. Actuar así significa obrar en contra del interés público. Para garantizar que se actúe buscando tal interés se requieren de ciertos valores instrumentales o extrínsecos. Tal es el propósito de la siguiente sección.

\section{Valores extrínsecos en la ética pública}

Una vez definido el interés público como el fin del Estado que se traduce en el respeto a las libertades y la prestación de ciertos servicios públicos por parte de los órganos gubernamentales, procede analizar cómo debe ser la conducta de los servidores públicos que conforman esos órganos a fin de que siempre se encaminen a dicho fin. Al efecto, proponemos los siguientes valores extrínsecos por ser los que dirigirían los actos de los servidores públicos hacia interés público:

1. Responsabilidad.

2. Objetividad.

3. Imparcialidad.

4. Razonabilidad.

5. Publicidad.

6. Solidaridad.

7. Prudencia.

8. Instrumentalidad.

A continuación, se procederá a determinarlos.

16 Hannah Arendt, “¿Qué es la libertad?”, en Entre el pasado y el futuro. Ocho ejercicios sobre la reflexión política, trad. de Ana Poljak, Península, Barcelona, 1996, pp. 155-184. 


\subsection{Responsabilidad}

Uno de los valores más importantes para garantizar el interés público es la responsabilidad. Su relevancia se encuentra en que los servidores públicos tienen el deber de fomentar el bienestar común de los individuos, por lo que su existencia responde a este valor intrínseco. Si fallan en llevar a cabo su tarea o si cometen ilícitos que la comprometen, el servidor público no cumple con su deber y deberá responder sobre sus acciones. Por otro lado, los servidores públicos deben de tener una actitud responsable, no solo evitando ser llamados a rendir cuentas por lo que hicieron, sino siendo proactivos para que los fines del Estado que se le encomiendan puedan ser cumplidos. Por esta razón, el valor de la responsabilidad es instrumental al interés público.

La teoría de la responsabilidad se remonta hasta los pensadores griegos, siendo el principal, en este tema, Aristóteles (384 a. e. c. - 322 a. e. c.). Para este, la responsabilidad estaba directamente asociada con el concepto de voluntariedad. Dicho de otra forma, para que una acción pudiese ser considerada como responsable tendría que haber sido hecha con la participación de la voluntad del agente, de otra manera, la acción no podría ser responsable ni sujeta a una acción penal, sino que, por el contrario, sería objeto de la indulgencia o la compasión. Así, dice Aristóteles: "Dado que la virtud se refiere a pasiones y acciones, y que, mientras las voluntarias son objeto de alabanzas o reproches, las involuntarias lo son de indulgencia y, a veces, de compasión"17. De este modo, una verdadera acción responsable tiene que provenir de la voluntad, esto es, de la libre elección. Esta voluntad no puede ser ignorante de las leyes o de un rango de consecuencias de la acción que sean posibles y razonables. La ignorancia que es digna de indulgencia proviene de los factores externos que no pudieron haber sido conocidos por el agente y que llevaron a un acto digno de castigo, aunque, en este caso, sería digno de perdón ${ }^{18}$. Una segunda forma se refiere a la fuerza mayor donde no puede evitar la acción y por tanto no se es responsable de ella.

Otro factor importante para esta teoría de la responsabilidad es el papel de la deliberación. En efecto, sobre los actos de los que somos responsables deliberamos, en el sentido de que somos agentes y tenemos control sobre si realizarlos o no; es decir, poseemos la capacidad de alterar, con el uso de nuestras facultades, el curso de los acontecimientos. En ese sentido, la responsabilidad afecta tan solo a las acciones que se encuentran bajo nuestro control y cuyas consecuencias son hasta cierto punto previsibles. Así, dice Aristóteles: "Deliberamos, entonces, sobre lo que está en nuestro poder y es realizable...En efecto, se consideran como causas la naturaleza, la necesidad y el azar, la inteligencia y todo lo que depende del hombre. Y todos los seres humanos deliberan sobre lo que ellos mismos pueden hacer"19. Cabe mencionar que actuar de este modo se corresponde con actuar según la phrónesis, es decir, la prudencia, como veremos más adelante.

Por lo anterior, se observa que la teoría clásica de la responsabilidad responde a dos conceptos fundamentales: la voluntariedad y la deliberación, correspondiéndose, esta última, con la phrónesis en la ejecución de la acción. Una acción, por tanto, es deliberada cuando fue elegida libremente y cuando fue reflexionada previamente

\footnotetext{
Aristóteles, Ética nicomaquea, Gredos, Madrid, 1985, pp. 178-179.

Ibidem.

Ibid., p. 110.
} 
sopesando las posibles consecuencias que se hallan bajo el control del agente. No obstante, lo anterior presenta el problema de que se trata de una responsabilidad que, si bien surge del agente, se mide a partir de las acciones cometidas ex post facto. Sobre este punto es importante subrayar el carácter pasado de la acción. Se trata pues, de una responsabilidad que mira al pasado de las acciones y que no es proactiva. Una persona guiada por este tipo de responsabilidad actuaría simplemente de manera pasiva, evitando en lo posible cometer actos que después pudiesen ser llevados al juicio de la opinión pública o de la ley. Es en su totalidad un mero marco restrictivo que no prescribe un tipo de acción particular, sino simplemente llama la atención sobre lo que no se debe hacer, idealmente.

De este modo, a esta responsabilidad pasiva, le corresponde la restricción de las acciones que se pueden dar en un marco normativo. Así, por ejemplo, cuando se dice que se deben de cometer acciones responsables, lo que se dice realmente es que se deben cometer acciones que no hayan brotado de una mala voluntad - es importante recordar en este punto la voluntariedad de la teoría de la responsabilidad-, y menos todavía de una deliberación consciente de un mal resultado producto de las acciones cometidas.

En general los sistemas jurídicos que buscan regular el actuar de los servidores públicos se han centrado en esta responsabilidad pasiva. Estos sistemas se limitan a un conjunto de conductas consideradas ilícitas a las que le acompaña una amenaza de coerción con el objeto de prevenirlas o sancionarlas, si son cometidas. Ahora bien, dado que en este trabajo se busca un valor extrínseco que conduzca al bienestar general, en el caso de los servidores públicos, debe ampliarse este concepto hasta una teoría prescriptiva de acciones responsables, que no se hagan por miedo a las represalias futuras, sino por mor del valor intrínseco. Esta nueva forma de responsabilidad la denominamos responsabilidad activa.

Pero, ¿qué significa este actuar por mor del interés público asociado a la responsabilidad activa? Como se menciona más arriba, la responsabilidad pasiva parte de las acciones cometidas por el agente, pero no es eso lo que se busca, sino una responsabilidad que parta de lo que cuida el agente, es decir, de aquello por lo que es responsable. Cuando el agente prueba que cuida de lo que se le ha encomendado, entonces se tiene a una persona responsable.

Como ejemplo, se puede hablar de lo que se entiende cuando se piensa en padres responsables. Ellos tutelan generalmente a un pequeño individuo y usualmente no actúan en función de lo que no deben hacer por temor a represalias, sino que, por el contrario, el padre y la madre responsable cuidan a sus hijos y buscan que esté en las mejores condiciones posibles, es decir, actúa en función de su interés. Para lograrlo actúan de tal manera que mejora las condiciones de vida de los hijos sin que la ley se lo ordene explícitamente. De igual forma cuando un individuo decide dedicarse al servicio público debiera ser movido por el deseo o el compromiso de actuar por el interes público y no simplemente abstenerse de cometer aquellos actos ilícitos en el desempeño de sus funciones públicas.

Hans Jonas (1903-1993), en El principio de responsabilidad, llama a esta responsabilidad activa "responsabilidad por lo que se ha de hacer" ${ }^{20}$. Esta es una responsabilidad que no parte de la acción sino del objeto de la acción. Dice:

20 Hans Jonas, El principio de responsabilidad: Ensayo de una ética para la civilización tecnológica, Herder, Barcelona, 1995, pp. 163-164. 
Aquello "por lo" que soy responsable está fuera de mí, pero se halla en el campo de la acción de mi poder, remitido a él o amenazado por él. Ello contrapone al poder su derecho a la existencia, partiendo de lo que es o puede ser y, mediante la voluntad moral, lleva al poder a cumplir su deber. La cosa es cosa mía porque el poder es mío y tiene una relación causal precisamente con esa cosa. En su derecho intrínseco, lo dependiente se convierte en lo que manda; en su causalidad, lo poderoso se convierte en lo obligado ${ }^{21}$.

De la cita anterior puede extraerse que esta responsabilidad está subordinada al fin que es el cuidado de lo que ha sido encomendado y sobre lo que tiene poder el agente, y esa es la responsabilidad que se busca añadir en este trabajo: un valor extrínseco que se ajusta a la finalidad que se le encomendó al servidor público en el momento en que algún aspecto del interés público se puso a su cuidado.

Este enfoque tiene muchas ventajas, porque refiere específicamente a la naturaleza de lo que fue puesto al cuidado de una persona. Es decir, si se pone a un gato en manos de un cuidador, este tiene ciertas necesidades, en función de su naturaleza, que no se encuentran, por ejemplo, en una planta. De esta manera, se obtiene un concepto proactivo de la acción responsable. Así, una acción responsable es toda aquella que responde a la naturaleza de la cosa, de lo que es y de lo que puede llegar a ser. En suma, una acción responsable es aquella que promueve el desarrollo de las cualidades ínsitas de lo que se ha puesto bajo el cuidado del agente. Trasladado a la discusión del apartado anterior, la acción responsable relativa a los servidores públicos que resguardan el interés público es toda aquella que promueva el interés público que, a su vez, se subdivide en la vida y la libertad, mismas que son necesidades humanas. Esta es la responsabilidad del servidor público, y va mucho más allá de la evasión de las consecuencias de las acciones ilícitas o prohibidas y se relaciona directamente con la eficiencia de la labor que le fue encomendada, cuyo resultado se cristaliza en el bienestar efectivo de la comunidad.

Concerniente también a esta teoría de la responsabilidad activa, es su relación con el poder, el cual lo entendemos como la capacidad de los servidores públicos de alterar la realidad colectiva. Así, los órganos gubernamentales y aquellos que se encuentran al frente de los mismos tienen en sus manos tanto la preservación de la comunidad, como una serie de poderes que pueden poner en riesgo o beneficiar a la misma. De modo que los servidores públicos se reputarán como responsables cuando sus acciones den como resultado un beneficio para el interés público.

Esta responsabilidad activa es, a su vez, un principio de la ética utilitarista. En efecto, esta doctrina ética nos habla de que debe de maximizarse la felicidad general y tener siempre en mente las consecuencias que puedan acaecer sobre los afectados ante cualquier acción de corte político, social o individual ${ }^{22}$. Lo bueno será entonces lo que tenga una consecuencia positiva en los estados emocionales que cada individuo considera valiosos y que el utilitarismo identifica con la felicidad.

Por esta razón, dentro de los valores utilitarios, la responsabilidad activa es el más importante, porque es el que, de ser cumplido cabalmente, llevaría a la consecución del interés público. No obstante, este valor no es el único deseable, como veremos más adelante.

22 Stuart Hampshire, "La moral y el pesimismo", en Stuart Hampshire (comp.), Moral pública y privada, Fondo de Cultura Económica, México, 1993, pp. 11-36. 


\subsection{Objetividad}

Una de las controversias que surgen de lo expuesto en la segunda sección es el conflicto del interés público con el individual. Como ha quedado arriba anotado, este interés público lo entendemos como los bienes comunes a toda la comunidad que son indispensables para su preservación y para el desarrollo de sus capacidades. Esto lo ha asentado la misma comunidad en su derecho y, por ende, se concibe como objetivo al ser compartido por todos. Así, es más objetivo que algo que solo es deseado por uno, situación esta última que, al ser relativo a un sujeto, será considerado en adelante como valor subjetivo. La razón por la que aquello que es deseado por todos es objetivo radica en que, si algo puede ser deseado en comunidad y no solo por unos cuantos, debe de ser deseado no por las inclinaciones individuales de cada uno, sino por lo que cualquier persona en la misma situación consideraría deseable, por lo que se objetiva el valor pero no en sí mismo, sino respecto a la comunidad humana, de ahí que se reconozca al interés público como un valor objetivo.

En relación con esto ya hemos hablado de Kant, pues, en efecto, lo que hace que un valor sea universal y que pueda transformarse en máxima con atribuciones de ley moral, es precisamente que lo pueda desear para uno y para todos. Al respecto Villoro afirma:

Lo que demuestra que un valor no es objetivo, sino relativo a un sujeto, es que responde solamente a su deseo, a su estimación exclusiva y no puede, por lo tanto, ser compartido. En la medida en que podamos considerar un valor como deseable con independencia de los deseos exclusivos de un sujeto, podemos pretender a su objetividad $^{23}$.

Este valor específico es fundamental para hablar de una acción responsable en el sentido activo de la palabra. La acción responsable, que debe orientar al servidor público, es únicamente aquella que tiene la propiedad de estar libre de toda inclinación meramente personal. De ser así, entonces la acción se hace en torno al interés público, cumpliendo por tanto el requisito de objetividad.

\subsection{Imparcialidad}

Un valor relacionado a la objetividad, pero sui generis, es el de la imparcialidad. El primero refiere simplemente a no cometer acciones en busca del interés de un individuo; no obstante, la imparcialidad refiere a un estado mental que se relaciona directamente con la etapa de la deliberación de la acción responsable. Este estado de la mente lo que propicia es que las decisiones sean tomadas sin intervención de los deseos individuales, lo que permite, en última instancia, evaluar los deseos de los otros de una manera no contaminada por los deseos propios. Tal visión de las cosas, es una visión imparcial.

Esta misma es un valor porque las acciones que se toman imparcialmente tienen la propiedad de buscar el mayor beneficio colectivo sin discriminar entre las per-

23 Villoro, El poder y el valor, p. 59. 
sonas. Por lo tanto, lo que se encuentra abriendo la mente a la postura del otro es una tonalidad objetiva que baña a la acción, y esa, entre otros valores posibles, es la imparcialidad.

El desprendimiento de nuestros deseos exclusivos y excluyentes permite poner entre paréntesis la visión de los valores enturbiada por los apetitos individuales. Entonces estamos en posición de ver el mundo desde el punto de vista valorativo de cualquier otro miembro de la asociación, que no coincidiera con nuestros deseos. Al intentar ver el mundo desprendido de mis deseos exclusivos, puedo considerar a los demás con imparcialidad y juzgar de los intereses ajenos con la misma ecuanimidad con que podría juzgar de los propios. La postura desprendida abre al diálogo y a la comprensión de las posiciones ajenas. Mediante un proceso de comunicación, en que los interlocutores dejaran de lado sus intereses excluyentes, se puede entonces llegar a determinar lo que sería objeto de una aceptación general ${ }^{24}$.

De lo dicho por Villoro puede interpretarse que el valor de la imparcialidad permite tomar decisiones que no están enturbiadas por los intereses particulares, y abre paso a un diálogo que observa, desde una perspectiva más amplia y libre de prejuicios, la toma de decisiones ${ }^{25}$. Dicho de otra manera, especifica la deliberación, vista más arriba, con el requisito de ser imparcial y abierta al diálogo, de modo que se busque el interés público.

Para lograr lo anterior resulta interesante la postura de Edmund Husserl (18591938) quién proponía "poner entre paréntesis"26 el objeto a deliberar. Con ello se refiere a una parte del método fenomenológico — inventado por él_ que busca hacer una suspensión del juicio - epojé- de todo lo que sabemos respecto de un objeto de conocimiento cualquiera. El propósito de hacer esto es, precisamente, liberar a la mente de los supuestos —o conocimientos previos - sobre la cosa para poder entonces captarla en toda su pureza ${ }^{27}$. Este estado que no reconoce nada como ya dado, sino que suspende el juicio sobre el tema a tratar, es lo que podríamos llamar una visión imparcial, libre de prejuicios, cuyo beneficio es dejar a la cosa mostrarse tal y como es y no contaminarla, en lo posible, con los prejuicios con los que nos hemos acostumbrado ya a vivir.

La visión imparcial, por lo tanto, no es otra cosa que la visión que puede denominarse cientifica, que busca la verdad del objeto tal como se manifiesta. Esto debe compartirse por los servidores públicos, pues también buscan la verdad respecto a cuál es la mejor decisión que pueden tomar para lograr sus objetivos o incluso, en un plano más fundamental, cuáles deben ser estos mismos. Sin mirar características como género, preferencias religiosas, etnicidad, sexo, etc. Una vez que se haya alcanzado esta visión libre de prejuicios entonces se habrá alcanzado la imparcialidad.

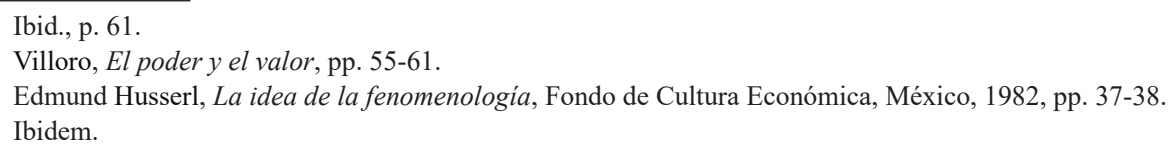




\subsection{Solidaridad}

Un modo de la voluntad que debe de pertenecer al sujeto que busque actuar de manera buena es, precisamente, la buena voluntad, concepto que ya veíamos en el primer apartado con Kant. Esta implica el deseo de actuar correctamente, sin embargo, cuando esta disposición de la voluntad se aplica al ámbito público, se transforma en solidaridad. Esto es así porque una comunidad refiere a algo que va más allá del sujeto que comete la acción, la buena voluntad tratándose del servicio público entonces es siempre solidaria con el otro. A su vez, la acción realizada con esta buena voluntad es portadora de la propiedad de ser solidaria y, por tanto, se encuentra en la acción el valor objetivo de la solidaridad, pudiendo así llamarla acción solidaria.

Este valor implica simplemente que el agente de la acción está en condiciones de tomar decisiones, no en favor de sí mismo, sino de todos. De esta manera, la solidaridad estaría relacionada directamente con la objetividad y la imparcialidad. Aunque con la diferencia de que aquella es una acción que busca el beneficio de todos en base a un compromiso particular, que hace al servidor público ser solidario, y esto es un sentimiento que parte de una idea de pertenencia a la comunidad. Por lo tanto, quien busque ser servidor público deberá tomar decisiones solidarias con los intereses de la comunidad, e idealmente no estar influenciado por decisiones de clases sociales o sectores particulares que sean subconjuntos de la comunidad. En alusión a esto, el filósofo mexicano apunta:

Todos pertenecemos a comunidades de las que nos consideramos parte: escuelas, instituciones, asociaciones, clases sociales, pueblos, naciones. En muchos momentos estamos obligados a distinguir entre nuestro interés y el interés del todo al que pertenecemos, en cuanto tal todo. En una situación de conflicto, esa distinción se nos hace clara y perentoria. ¿Quién no es capaz de distinguir sus deseos personales de los de la institución, la comunidad, la nación de la cual forma parte? Cuanto más solidario con su comunidad sea un individuo mayor será esa capacidad. Pero solo podrá hacerlo, al "poner entre paréntesis" sus deseos excluyentes de los demás, y mirar por el interés del todo ${ }^{28}$.

De esta forma, todo servidor público no debe de ser solo parte de la comunidad, sino sentirse parte de la comunidad. Cuando uno elige servir al interés público debiera comprometerse con él, resultando así que buscará el beneficio de la comunidad por el carácter de sus acciones que tienen la propiedad de ser solidarias, y eso las hace valiosas.

\subsection{Publicidad}

Uno de los valores más importantes para el actuar de los servidores públicos es la publicidad. Este se entiende, como pensara Nora Rabotnikof, como lo común y lo general; como lo visible o lo manifiesto, y como lo abierto. De estos tres sentidos, el propio de la actuación de los servidores públicos es el actuar de manera visible y manifiesta. Rabotnikof lo entiende de la siguiente manera:

28 Villoro, El poder y el valor, p. 62. 
El segundo criterio refiere a la visibilidad [contra] el ocultamiento, a lo que es ostensible y manifiesto [contra] lo secreto. Público designa aquí lo que es visible y se despliega a la luz del día en oposición a lo privado entendido como aquello que se sustrae a la mirada, a la comunicación y al examen... ${ }^{29}$.

Esto, puede entenderse como un valor, porque es una cualidad de la acción. Quien actúa públicamente se presenta ante la sociedad como abierto al escrutinio. Porque todas las acciones de los servidores públicos deben de estar supeditadas a la posibilidad de ser evaluadas por la opinión pública, por ello y dado que las acciones públicas conciernen a todos, es un valor deseable por sí mismo susceptible a ser universalizable.

No obstante, Immanuel Kant hace un interesante análisis acerca de la publicidad, esto es: que sin publicidad no hay justicia, porque la justicia no es posible en secreto. En ese sentido, establece una fórmula trascendental que prescinde de toda materia en el derecho público. En ese sentido, la publicidad para Kant es un principio a priori, es decir, formal, por lo que no entra como contenido del que podamos después hacer una síntesis en el apartado siguiente, sino que, él mismo, es ya un imperativo carente de toda forma. Dice Kant:

Si prescindimos, pues, de todo el contenido empírico que hay en el concepto del derecho político y del derecho de gentes - como es, por ejemplo, la maldad de la humana naturaleza que hace necesaria la coacción-, hallamos la proposición siguiente que bien puede llamarse "fórmula trascendental" del derecho público:

"Las acciones referentes al derecho de otros hombres son injustas, si su máxima no admite publicidad" 30 .

Esta fórmula la llama Kant un principio jurídico y basa su argumentación en la idea de que todo lo que se hace en secreto es públicamente censurable y, por lo tanto, injusto. Así, se observa que la publicidad es un principio formal de la misma clase que el imperativo categórico cuya función es determinar si la máxima es justa. Ya se regresará a ello más adelante; por ahora baste con mencionar que la publicidad se deberá de aplicar a todas las máximas del derecho público. Al respecto Nora Rabotnikof dice:

Necesitar de la publicidad significaría aquí necesitar del concurso o de la aprobación del público. Kant...se está refiriendo...a una suerte de aprobación o prueba de la concordancia de la norma con las condiciones para la felicidad privada, es decir, con los derechos individuales ${ }^{31}$.

Desde esta perspectiva, ninguna máxima que sea susceptible de producir desaprobación en el público se puede decir que sea justa. En ese sentido, Kant piensa

29 Nora Rabotnikof, El espacio público y la democracia moderna, IFE, México, 1997.

30 Inmanuel Kant, La paz perpetua, trad. de F. Rivera Pastor, Biblioteca Virtual Miguel de Cervantes, Alicante, 1999 (ed. digital basada en la edición de Espasa Calpe, Madrid, 1979). Disponible en: http://www.cervantesvirtual.com/obra/la-paz-perpetua--0/ (1-8-2017). El pasaje citado corresponde al Apéndice II, disponible en: http://www.cervantesvirtual.com/obra-visor/la-paz-perpetua--0/html/fefe81ac-82b1-11dfacc7-002185ce6064_3.html\#I_13_(1-8-2017).

31 Rabotnikof, En busca de un lugar común, p. 61. 
que la publicidad es un requisito fundamental de las máximas para ser consideradas justas, pues ¿qué otro motivo hay para sustraer del escrutinio del público una acción que su inconcordancia con ese mismo interés? En ese sentido, puede extenderse la definición en la siguiente proposición: toda acción que se sustrae del escrutinio público es susceptible de ser considerada en contra del interés público, por lo que todas las acciones deberán de estar enderezadas al principio jurídico de la publicidad.

\subsection{Razonabilidad}

Un tipo claro de valor que se infiere de lo dicho es el de razonabilidad. Como hemos visto más arriba, la razón es la encargada de entregar el imperativo categórico, así como las acciones que son o no deseables. Este proceso solo puede ser logrado a partir del uso de la razón práctica ${ }^{32}$ y requiere que las acciones que van a tomarse sean hechas conforme a este principio. Al respecto, Villoro nos dice que el modo particular de la razón es la razón valorativa:

Pero el proceso de justificación puede seguir otra línea. En ella se encuentra con la ética. Para fundar su pretensión de objetividad, puede acudir a otra función de la razón...Para ese ejercicio no se presta la razón teórica; es menester otro uso de la razón: el que establece la validez objetiva de los valores, con independencia de las actitudes particulares de cada grupo. Esta es una razón valorativa ${ }^{33}$.

En esta cita se apunta que debe de haber un proceso racional que justifique la acción como correspondiente al interés general o público. Eso impide que las acciones sean meramente un instrumento ideológico de un interés particular que pretende volverse un interés público simplemente porque es la ideología dominante, cosa que, hay que decirlo, es un proceso ciertamente irracional. Por el contrario, el proceso argumentativo que responde a la razón valorativa es lo que caracteriza a las acciones que promueven el interés público; y esto solo puede hacerse mediante un uso de la razón a partir de las normas y principios establecidos en el derecho de una comunidad como las guías de la acción del servicio público hacia el interés público. De modo que el servidor público debe razonar sus decisiones a partir de las obligaciones y derechos establecidos en el orden jurídico de su comunidad como fines del Estado.

A su vez, esto está asociado directamente con el concepto de "suspensión del juicio" 34 de la fenomenología de Husserl, pues justamente el servidor público debe de actuar independientemente de las valoraciones que ha aprendido, pero esta actuación no puede ser salvaje, sino que requiere que haya un proceso argumentativo que permita justificar las acciones. Por esta razón, si bien se deben de abandonar todos los prejuicios que se tienen en torno a cualquier asunto que sea sujeto de la acción de un servidor público, ello simplemente implica liberar a la razón de las cadenas de los prejuicios que vienen ya desde la infancia. A su vez, si bien en la vida privada cualquier persona puede optar por ellos, en la vida pública y su respectiva toma de decisiones se debe suspender para tomar una acción adecuada y fundada en la razón

\footnotetext{
Immanuel Kant, Crítica de la razón práctica, Losada, Buenos Aires, 1968.

Rabotnikof, En busca de un lugar común, p. 79.

34 Husserl, La idea de la fenomenología, pp. 67-68.
} 
y en el sistema normativo que regula a la comunidad y que constituye la guía de todas sus acciones.

\subsection{Prudencia}

La prudencia es uno de los dos valores que aseguran que la acción de los servidores públicos tenga contacto con la realidad. En efecto, prudencia la podemos definir simplemente como sabiduría práctica, es decir, como aquel valor que relaciona la acción política con las posibles consecuencias de los actos del servidor público. En ese sentido, es un cálculo de relaciones entre los valores y el contexto en el cual es adecuado —o prudente — aplicarlos. Presumiblemente por este motivo Villoro escribe lo siguiente:

Una voluntad ética considera los valores objetivos por realizar en cada caso. Sus elecciones y decisiones son concretas. En cada circunstancia debe ponderar los valores distintos que entran en conflicto, las posibilidades de su realización y sus consecuencias previsibles. Esa reflexión no puede regirse por leyes generales, es obra de un conocimiento personal guiado por la prudencia. Responde a una racionalidad de juicio contextual ${ }^{35}$.

Este cálculo es fundamental en la acción de los servidores públicos, pero refiere simplemente a los valores que son instrumentales a un fin determinado, pero que no son universalizables. Así, por ejemplo, el valor de hacer una política pública que busque resolver el problema de la pobreza deberá ser hecha con objetividad, imparcialidad, responsabilidad, etc., de manera irrestricta. Pero los valores especiales que se utilicen para lograr el fin particular, deberán de tener otro tratamiento. En este caso podría considerarse que apoyos económicos significativos y capacitación son los mejores medios y, por ello, son indispensables para combatir el problema. Pero tan solo se tendría que cambiar la finalidad, por ejemplo, a reducir el gasto público para los partidos políticos para que el valor de entregar mayores cantidades de dinero sea ya lo contrario al fin deseado. De ello resulta que los valores derivados de la finalidad específica de la acción gubernamental son los valores contingentes y no universales, como son aquellos que estamos tratando en este lugar.

En ese sentido, la prudencia es un valor que siempre tiene que tener en cuenta a las consecuencias de los actos en cuanto a la realización de los fines. En segundo lugar, deberá de tener en cuenta que las acciones del gobierno no estén en contradicción con los valores de la ética pública. También deberá buscarse que el cálculo de la acción sea consciente. Esto último es importante porque cuando hay consciencia en los actos, las condiciones y las posibles consecuencias, los servidores públicos deben de ser capaces de asumir cualquier variable que se les presente de manera responsable. Ya sea que haya salido bien la acción o que se le haya ido de las manos.

$35 \quad$ Villoro, El poder y el valor, p. 247. 


\subsection{Instrumentalidad}

Otro valor, muy relacionado con el anterior, que encontramos en la ética pública es el de la instrumentalidad. En efecto, todo lo que se diga que va a hacerse debe poder realizarse en un futuro y no solo eso, debe garantizar los medios para que la acción pueda ser realizada. Todo esto va más allá de un mero discurso prescriptivo pues debe volverse siempre una acción efectiva. Este es un valor propio de los servidores públicos porque tienen poder para realizar las diversas acciones, el cual les fue conferido por la comunidad a través del derecho. Eso significa que dentro de sus capacidades está la de llevar o no a cabo tales o cuales acciones en pos del interés público.

A su vez, de acuerdo con Villoro, podemos afirmar que:

Una acción moral, tratándose del servicio público, no consiste solo en la proyección y disposición de realizar el bien común, sino en su realización efectiva en la comunidad. Los valores destinados a lograr el interés público deben poder cumplirse. Una ética pública debe tratar de la relación de los valores colectivos elegidos por la comunidad y plasmados en su ordenamiento jurídico con los hechos sociales que permitirían realizarlos. Por consiguiente, una ética pública tiene por temas:

1) Determinar cuáles son los valores comunes, dignos de ser estimados por cualquiera y que quedan plasmados en el derecho tras la deliberación colectiva al menos a través de sus representantes en una democracia.

2) Fundarlo en razones a través de un diálogo abierto que dé publicidad a las decisiones de modo que resulten en acciones derivadas de valores objetivos.

3) Indicar los principios normativos de las acciones que permite la realización del interés público ${ }^{36}$.

La instrumentalidad es uno de los valores más importantes de la acción responsable en un sentido positivo, pues aquí culmina toda la acción pública. La concreción del interés público, con su correspondiente consecución del bienestar general en función del interés público, es el objetivo de toda la ética pública cuyo fin es guiar los actos de los servidores públicos.

Ahora bien, la siguiente sección tiene como objetivo sintetizar estos valores con el imperativo categórico para obtener los principios que deberán posteriormente positivizarse en el derecho.

\section{Tránsito de los valores a los principios}

Ya en el primer apartado se veía que el principio ético se subdivide en una parte material y otra formal. Lo que ahora corresponde es hacer una síntesis entre ambas partes para construir así el grupo de principios que prescriben las acciones en torno al servicio público. El proceso consiste meramente en elaborar una máxima en relación con el valor para poder así entregar un principio ético que, al tener un carácter normativo, es posible incorporar al orden jurídico.

$36 \quad$ Ibid., pp. 73-74. 
Todos los principios que se ven en la tabla 1 tienen como característica el ser universales, es decir, ordenan de manera irrestricta en función de su universalidad que deriva de haber aplicado el imperativo categórico. Se advierte que en dicha tabla no se incluye el principio publicidad, pues, como vimos anteriormente se trata de una ley formal, lo mismo que el imperativo categórico. Por lo tanto, habría que añadir que todos los principios éticos con capacidad de incorporarse a un sistema normativo requieren ser públicos para ser conforme a derecho. Es decir, todas las acciones realizadas derivadas de estos principios deben hacerse a la luz para no ser injustas.

\begin{tabular}{|c|c|}
\hline Valor y su definición & $\begin{array}{l}\text { Principio a positivar mediante su inclu- } \\
\text { sión en las normas supremas o constitu- } \\
\text { cionales del orden jurídico. }\end{array}$ \\
\hline $\begin{array}{l}\text { Interés público (valor intrínseco): asegura- } \\
\text { ción de la vida y la libertad de elección de } \\
\text { los modos de vida que se encuentren dentro } \\
\text { de la ley y que sean considerados por el su- } \\
\text { jeto como propios de su felicidad. }\end{array}$ & $\begin{array}{l}\text { Todos los servidores públicos deberán ac- } \\
\text { tuar en pos del interés público, garantizando } \\
\text { que sus acciones sean consistentes con el } \\
\text { interés público y no con el interés particular. }\end{array}$ \\
\hline $\begin{array}{l}\text { Responsabilidad activa (valor extrínseco): } \\
\text { responsabilidad proactiva que busca realizar } \\
\text { acciones a favor del interés de lo que ha sido } \\
\text { puesto bajo el cuidado del agente. }\end{array}$ & $\begin{array}{l}\text { Todos los servidores públicos deberán ac- } \\
\text { tuar de manera que busquen el bien público } \\
\text { y, por ende, el desarrollo de la comunidad. }\end{array}$ \\
\hline $\begin{array}{l}\text { Objetividad (valor extrínseco): valor que, en } \\
\text { relación con una acción, posibilita que esta } \\
\text { sea compartida por todos. }\end{array}$ & $\begin{array}{l}\text { Los servidores públicos deberán garantizar } \\
\text { que sus acciones no sean válidas solo para } \\
\text { ellos, sino para toda la comunidad. }\end{array}$ \\
\hline $\begin{array}{l}\text { Imparcialidad (valor extrínseco): visión del } \\
\text { mundo que pone entre paréntesis - epojé- las } \\
\text { inclinaciones individuales para analizar de } \\
\text { manera libre de prejuicios las acciones a tomar. }\end{array}$ & $\begin{array}{l}\text { El actuar de los servidores públicos deberá } \\
\text { realizarse teniendo cuidado de no contami- } \\
\text { nar con prejuicios o ideas preconcebidas las } \\
\text { decisiones que se tomen desde su posición. }\end{array}$ \\
\hline $\begin{array}{l}\text { Solidaridad (valor extrínseco): sentimiento } \\
\text { de pertenencia a la comunidad. }\end{array}$ & $\begin{array}{l}\text { La acción del servidor público deberá reali- } \\
\text { zarse desde el supuesto de que pertenece a } \\
\text { la comunidad y, con ello, deberá buscar el } \\
\text { beneficio de la misma. }\end{array}$ \\
\hline $\begin{array}{l}\text { Razonabilidad (valor extrínseco): propiedad } \\
\text { de la acción por la que se justifica a través de } \\
\text { razones, ya sean jurídicas o éticas. }\end{array}$ & $\begin{array}{l}\text { Todo servidor público deberá revisar que } \\
\text { sus acciones se funden en razones válidas } \\
\text { que permitan asegurarle que respondan a las } \\
\text { normas jurídicas y a valores objetivos y no a } \\
\text { intereses personales. }\end{array}$ \\
\hline $\begin{array}{l}\text { Prudencia (valor extrínseco): valor por el } \\
\text { que se traza un puente entre la realidad so- } \\
\text { cial y la epistemología. Consiste en el cálcu- } \\
\text { lo de cuáles de estos son más propios de la } \\
\text { acción en función del contexto. }\end{array}$ & $\begin{array}{l}\text { Toda acción de los servidores públicos de- } \\
\text { berá tener en cuenta las consecuencias de las } \\
\text { acciones. }\end{array}$ \\
\hline $\begin{array}{l}\text { Instrumentalidad (valor extrínseco): propie- } \\
\text { dad de la acción que permite que lo que se } \\
\text { dice sea realizado en el futuro. }\end{array}$ & $\begin{array}{l}\text { Todo lo dicho por un servidor público debe- } \\
\text { rá acompañarse de los elementos para que la } \\
\text { acción se materialice. }\end{array}$ \\
\hline
\end{tabular}

Tabla 1. Relación de valores y el principio que los positiviza. 
La tabla 1 es el tránsito de los valores a los principios que deben regular el actuar de los servidores públicos. Así, resulta que no solo es necesario indicar de manera racional los valores deseables, sino que deben entregarse principios para que estos sean realizados y queridos por todo ser racional. Principios que tienen un carácter normativo; es decir, que pretenden regular la conducta de los servidores públicos de modo que, así enunciados, es posible incorporarlos al derecho dándoles un carácter heterónomo y coercible en el sentido de exigible para todo aquel que habiendo aceptado ser servidor público los incorpore como guía de todas sus funciones públicas. De modo que su incorporación dentro de las normas supremas o constitucionales los hagan exigibles jurídicamente.

\section{Conclusión}

La propuesta que se sigue de este trabajo es incorporar estos principios al orden jurídico y desarrollarlos en los sistemas normativos que rigen a los servidores públicos. Lo anterior fomenta el buen hacer de la función pública no solo guiando sus actividades mediante elementos de responsabilidad pasiva marcando actos ilícitos y sanciones, sino que también lo hace mediante la incorporación de principios éticos que guíen su actuación como resultado de valores objetivos tendentes al logro del interés público. Siendo el compromiso con dicho interés, a partir de la adopción de estos valores, el que permite que la actuación de los servidores no solo este inspirada por el miedo a una sanción sino por un compromiso con la búsqueda del bienestar general, objeto del interés público.

Si la persecución de la corrupción mediante el endurecimiento de las conductas ilícitas, el aumento de la vigilancia o la especialización de la persecución de las faltas no ha sido suficiente para acabar con este cáncer que aqueja a muchos de nuestros países, parece momento de buscar soluciones nuevas. Recuperar la posibilidad de contar con principios dentro del derecho que promuevan un actuar virtuoso por parte de los servidores públicos es necesario de cara a una situación de corrupción que se caracteriza, precisamente, como la falta de principios éticos que permitan un compromiso con el interés público y se constituyan en guías de la acción de los servidores públicos.

\section{Referencias bibliograficas}

Aristóteles, Ética nicomaquea, Gredos, Madrid, 1985.

—, Política, Gredos, Madrid, 1988.

Arendt, Hannah, “¿Qué es la libertad?”, en Entre el pasado y el futuro. Ocho ejercicios sobre la reflexión política, trad. de Ana Poljak, Península, Barcelona, 1996, pp. 155-184.

Brentano, Franz, Psicología desde un punto de vista empírico, trad. de José Gaos, Revista de Occidente, Madrid, 1935.

Ferrajoli, Luigi, Democracia y garantismo, ed. de Miguel Carbonell, Trotta, Madrid, 2008.

Ferrater Mora, José, Diccionario de filosofia, tomo II, quinta edición, Editorial Sudamericana, Buenos Aires, 1979.

Hampshire, Stuart, "La moral y el pesimismo", en Stuart Hampshire (comp.), Moral pública y privada, Fondo de Cultura Económica, México, 1993. 
Husserl, Edmund, La idea de la fenomenología, Fondo de Cultura Económica, México, 1982. Jonas, Hans, El principio de responsabilidad: Ensayo de una ética para la civilización tecnológica, Herder, Barcelona, 1995.

Kant, Immanuel, Crítica de la razón práctica, Losada, Buenos Aires, 1968.

—, La paz perpetua, trad. de F. Rivera Pastor, Biblioteca Virtual Miguel de Cervantes, Alicante, 1999 (ed. digital basada en edición de Espasa Calpe, Madrid, 1979). Disponible en: http://www.cervantesvirtual.com/nd/ark:/59851/bmchd7r6 (1-8-2017).

- Fundamentación de la metafísica de las costumbres, texto íntegro de la trad. de Manuel García Morente, ed. de Pedro M. Rosario Barbosa, San Juan, Puerto Rico, 2007. Publicado bajo licencia Creative Commons. Disponible en: https://pmrb.net/books/kantfund/fund_metaf_costumbres_vD.pdf (1-8-2017).

Mill, John Stuart, Utilitarismo. Un sistema de la lógica, Alianza Editorial, Madrid, 2014.

Persson, Ann; Rothstein, Bo y Teorell, Jan, The Failure of Anti-Corruption Policies. A Theoretical Mischaracterization of the Problem, QoG Working Paper Series 2010:19, The Quality of Government Institute, Department of Political Science, University of Gothenburg, Göteborg, Junio 2010.

Rabotnikof, Nora, El espacio público y la democracia moderna, IFE, México, 1997.

- En busca de un lugar común. El espacio público en la teoría política contemporánea, Instituto de Investigaciones Filosóficas, UNAM, México, 2005.

Rothstein, Bo y Theorell, Jan, "What is the Quality of Government? A Theory of Impartial Government Institutions": Governance: an International Journal of Policy, Administration, and Institutions, vol. 21, n. ${ }^{\circ} 2$ (2008), pp. 165-190.

Schopenhauer, Arthur, El mundo como voluntad y representación, vol. I, Trotta, Madrid, 2003.

Spinoza, Baruch, Ética demostrada según el orden geométrico, trad. de Vidal Peña, Orbis, Buenos Aires, 1983.

Unamuno, Miguel de, Del sentimiento trágico de la vida, Ediciones B, Barcelona, 1988.

Villoro, Luis, El poder y el valor. Fundamentos de una ética política, Fondo de Cultura Económica, México, 1997.

-, Los retos de la sociedad por venir: ensayos sobre justicia, democracia y multiculturalismo, Fondo de Cultura Económica, México, 2007.

—, Estado plural, pluralidad de culturas, Editorial Paidós, México, 2001. 